\title{
El sentido de la representación política: de la evolución democrática a la involución totalitaria
}

\author{
POR DEBORA BURSZTYN $\left({ }^{*}\right)$ Y ALEJANDRA P. DÍAZ $(* *)$
}

\begin{abstract}
Sumario: I. Introducción.- II. El origen y sus primeros pasos.- III. Los aportes de la modernidad: representación y liberalismo.- IV. La irrupción de las masas en el escenario político.- V. La ampliación de la democracia.- VI. El ascenso de las fuerzas iliberales y la destrucción de la democracia.- VII. La fatiga de la democracia al inicio del siglo XXI.VIII. Conclusión.- IX. Bibliografía.
\end{abstract}

Resumen: el camino hacia la comprensión democrática en los inicios del sigloXXI nos permite mirar hacia atrás y visualizar las condiciones en que este sistema ha venido desarrollándose en los siglos precedentes. Sus fortalezas y debilidades se comprenden mejor cuando se compara la forma en que se ha manifestado ante distintas crisis. El final del siglo XIX nos enfrentó con el nacimiento de los nacionalismos que nos instaló ante la crisis del mundo liberal, que no brindaba respuestas a un mundo en cambio. Las expresiones de los autores de esa época no solo responden a sus propios dilemas, sino que también nos permiten visualizar los conflictos a los que podemos estar enfrentándonos.

Palabras claves: democracia - liberalismo - masa - crisis - representación

The meaning of politica representation: from democratic evolution to totalitarian involution

Abstract: the road to democratic understanding at the beginning of the 21st century allows us to look back and visualise the conditions under which this system has been developing over the preceding centuries. Its strengths and weaknesses can be better understood by comparing the way it has manifested itself in the face of different crisis. The end of the 19th century brought us face to face with the birth of nationalism,

$\left({ }^{*}\right)$ Abogada, Universidad de Buenos Aires. Prof. de Teoría del Estado, Facultad de Derecho, Universidad de Buenos Aires y de Derecho Político, Facultad de Derecho y Ciencias Políticas, Universidad Nacional de La Matanza.

(**) Lic. en Ciencia Política, Universidad de Buenos Aires. Prof. de Ciencia Política en el Ciclo Básico Común, Universidad de Buenos Aires, de Teoría del Estado y Derecho de la Integración, Facultad de Derecho, Universidad de Buenos Aires. 
which brought us face to face with the crisis of the liberal world, which did not provide answers to a changing world. The expressions of the authors of that period not only respond to their own dilemmas, but also allow us to visualize the conflicts we may be facing.

Keywords: democracy - liberalism - mass - crisis - representation

\section{Introducción}

La democracia es una forma de gobierno ampliamente extendida en nuestros días y cuya valoración positiva no está en discusión. Sabemos por la experiencia histórica que, entendida como régimen, se trata del modelo que mejor puede garantizarnos vivir en un Estado de derecho donde se garanticen las libertades y los derechos de todos los seres humanos.

Datamos su nacimiento en el siglo V a.C, en un contexto donde resultaba fuertemente cuestionada por los grandes pensadores que trascendieron su época y por las élites que veían en ella la pérdida de sus privilegios.

Nuestra democracia no es exactamente aquella, sino como forma inspirada en aquel paradigma, pero con un condimento nuevo, propio de la modernidad: la representación. Por ello, hoy este modelo se reconoce como democracia representativa, para diferenciarla de la antigua y, a la vez, dar una descripción inicial acerca de lo que se habla.

La democracia representativa acarrea como un acompañante indeseado la crisis de la representación política, que resulta ínsito a la modernidad. La sensación de que los elegidos traicionan a sus representados resulta tan común como inevitable.

La sociedad democrática que surge en el siglo XIX no encuentra su coherencia a partir de sus diferencias sino a partir de sus similitudes, y allí reside la abstracción. Se proclama a cada miembro de la sociedad como ciudadano que se construye sobre la base de generar una encarnación social para representarlo.

Esta sensación de crisis, que se articula a partir de considerar que la democracia no es suficiente, que excluye a las mayorías dejando el poder en manos de las élites (que podrían identificarse en los partidos políticos) no es nueva. Como tampoco es nuevo el fenómeno de los regímenes democráticos que, en nombre de la democracia, van tomando formas de modalidad autoritaria concentrando el poder. "El problema es que esta representatividad implica la introyección del autoritarismo - entendido como la negación de lo público y de la efectiva legalidad del 
estado democrático, y por lo tanto, de la ciudadanía- (...)” (Abal Medina, 2004, p. 121).

La democracia necesita del pluralismo en los distintos ámbitos de la sociedad. Pero, por otro lado, como sostiene José Nun (2015) en su libro Democracia $i G o-$ bierno del pueblo o Gobierno de los políticos?, las democracias representativas no son todas iguales, aunque entre ellas conservan ciertas características que las asimilan. Esto se debe a que los diferentes actores no juegan de igual forman en todo el mundo democrático.

Muchas veces se ha caracterizado a la democracia moderna como democracia inconclusa, como una promesa incumplida, como una utopía que fracasa al no poder concretarse en la realidad tal y como se pretende. Por otra parte, hay quienes piensan que la democracia se basa en una contradicción. Si pensamos que se fomenta sobre la pluralidad, en ella existe la contradicción por excelencia: la diversidad. La democracia resulta ser un proceso por el cual se explora, en busca de resolver esas contradicciones. ¿Cómo convertir en iguales a individuos con múltiples diferencias? Una de las respuestas deviene en considerarlas en su forma abstracta al garantizar la igualdad ante la ley y apoyándose en una batería de libertades y derechos, pero la respuesta no llega a ser completamente satisfactoria.

A lo largo de la historia de la democracia, cuestiones como las referenciadas se encontraron en constante discusión. Nos interesa poder desarrollar un somero derrotero de la conceptualización y de las discusiones que se dieron a través de los tiempos sobre estos interrogantes, que hoy nos siguen interpelando.

\section{El origen y sus primeros pasos}

Probablemente cuando se inicia una conversación acerca de la democracia, la primera imagen que acude a nuestro inconsciente se traduce en la de un grupo de ciudadanos reunidos en medio de una plaza en Asamblea, a la que se los convoca para tomar decisiones. En definitiva, el poder del demos en acción.

La antigüedad clásica nos conduce, a partir del término demos, a pensar en el gobierno del pueblo, de los ciudadanos. La primera manifestación de este fenómeno la encontramos en el siglo V a.C, en lo que fuera caracterizado como el gobierno de muchos, de la multitud: el gobierno del número. Aristóteles le dará el nombre de Politeia.

La caída de la experiencia democrática ateniense y el advenimiento de Roma hacen derivar esta terminología hacia una nueva caracterización: la República. La misma es respuesta a un dilema que no se logrará resolver en mucho tiempo. Robert Dahl (2004) sostiene: 
(...) a medida que la Republica Romana se fue expandiendo, fue confiriendo la ciudadanía en diversos grados a muchos de quienes habitaban sus expandidos límites. Pero debido a que las asambleas romanas siguieron reuniéndose en el Foro, la mayor parte de ciudadanos que no habitaban dentro o cerca de la ciudad no podían participar, por ende, quedaban de hecho excluidos del demos. A pesar de su reputación de prácticos y creativos, y no obstante los numerosos cambios en la estructura del gobierno romano a lo largo de los siglos, los romanos jamás solucionaron este problema (...) (p. 17).

Luego, la República romana, derrocada por la Dictadura y el Imperio, legará al mundo medieval la discusión acerca de la legitimidad de la autoridad y la distinción entre la titularidad y el ejercicio. El mundo medieval tomará la herencia que Ulpiano y Juliano les legaron: entender o aprender acerca de la fuente / poseedor del poder, sobre el establecimiento del orden y las reglas, o se traslada o se cede. Si se traslada a quien detenta la autoridad, este no solo reviste el ejercicio del poder, sino que también se transforma en su titular. Si el poder se cede, quien lo recibe solo posee su ejercicio y la titularidad permanece en la fuente.

De la mano de Maquiavelo se reformará el concepto de "República" (como alternativa a kois principados), que no se identificará con la democracia como gobierno popular, sino que se consolidará como una suerte de forma de gobierno donde el poder no se haya concentrado sino distribuido en cuerpos colegiados (idealización que los revolucionarios franceses del siglo XVIII tomarán en su variable más radicalizada).

\section{Los aportes de la modernidad: representación y liberalismo}

Las Revoluciones políticas inglesas y las teorías contractualistas esbozadas durante el siglo XVII darán, a partir del pensamiento filosófico político, la caracterización de estas nuevas manifestaciones institucionales. James Harrington, al describir el republicanismo inglés de la época, planteó, en una suerte de confusión entre República y democracia, principios igualitarios que anclarán formalmente en la rotación de magistrados legitimados en la elección de los ciudadanos y materialmente en la ley agraria de distribución ecuánime de la tierra.

Jean Jacques Rousseau, bajo los auspicios de la voluntad general y de la soberanía, constituirá una coincidencia entre el ideal republicano y el ideal democrático, al concentrar en ella la capacidad de hacer las leyes y administrar las instituciones. Así podemos ver la república como forma de estado o de cuerpo político y a la democracia como forma de gobierno. 
El estado Liberal, nacido en el contexto de la Revolución Gloriosa y del pensamiento de John Locke, le permitirá a Benjamin Constant hablar de la libertad de los antiguos y de la libertad de los modernos. La libertad de los antiguos la comprende como la participación directa en la formación de leyes a través del cuerpo político y lo asimila a la democracia directa. La libertad de los modernos, la libertad individual respecto del estado que se manifiesta de modo concreto en las libertades políticas (que no necesariamente debe extenderse a todos los ciudadanos)(1). La distinción efectuada por Constant permite describirlo desde una perspectiva analítica descriptiva y una axiológica / valorativa. La democracia directa frente a la democracia representativa. La democracia directa bajo una perspectiva negativa consecuencia de su comprensión como gobierno dirigido por el pueblo al que se atribuye los peores vicios: la ignorancia, la incompetencia, la agresión. La democracia, en estos términos, nace de la violencia y se conserva por la violencia. La democracia de los modernos, representativa, no pertenece al pueblo, pertenece a los ciudadanos como suma de individuos que conforman la sociedad a la que pertenecen y se restringe a ella. Se integran en su pensamiento el disfrute de los derechos individuales en clave de participación ciudadana y cooperación social (Aguilar, 2008).

Los principios sentados por Constant y receptados por autores de la talla de Alexis de Tocqueville y John Stuart Mill, arriban a la conclusión de la idea que la única democracia compatible con el Estado Liberal es aquella que reconocerá y garantizará los derechos naturales, es decir, la democracia representativa plasmada en el parlamentarismo inglés y en el presidencialismo norteamericano. La tarea de hacer las leyes le corresponderá a un cuerpo restringido de representantes elegidos por aquellos ciudadanos a los que se les reconoce derechos políticos, que devienen de la reivindicación de la libertad conquistada frente al poder absoluto traducido en la posibilidad de elegir y ser elegido, capacidad jurídica específica con acento en la participación.

Así, puede considerarse que la democracia de los antiguos deviene de condiciones históricas cambiantes, en tanto que la democracia de los modernos nace a partir de una distinta concepción moral del mundo, a partir de la convalidación de dos principios básicos: 1) la existencia de un órgano cuyas decisiones son tomadas por órganos colegiados formados por representantes; 2) estos representantes reflejan las distinciones entre grupos de opinión o interés que se manifiestan en el interior de una sociedad.

(1) Sobre esta postura se parará Isaiah Berlin al describir en 1958 la distinción entre la libertad positiva y la libertad negativa, en clara referencia a la ausencia de barreras o interferencias en el ejercicio de la libertad que plantea la tradición anglosajona. 
La soberanía del pueblo frente a la democracia representativa nace de la desincorporación del poder (el momento en el cual el monarca deja de personificar a la nación en su persona) y forma una sociedad política nueva que se articula sobre la base de un sistema de garantías fundamentales de las cuales resultan titulares los ciudadanos, la abolición de la distinción de órdenes y la formación de uno o varios órganos de autoridad pública delegadas a favor del sufragio.

Estas son las observaciones efectuadas por Alexis de Tocqueville. Su descripción de la lenta e inexorable igualación de las condiciones se gesta de la destrucción de las jerarquías de la sociedad aristocrática y percibe una nueva forma de sociedad que resulta homogénea, producto de la vinculación y la uniformidad generada a partir de los nuevos tipos de dependencia, lo que provoca el nacimiento de una nueva concepción de autoridad. La desincorporación del poder, el hecho de que la autoridad política deja de gozar de legitimidad absoluta (rey titular de la soberana razón y la soberana justicia bajo el formato de lo mortal y lo inmortal) se proyecta hacia cuerpos representativos cuyo poder carece de capacidad de encarnación. La concepción de la idea de la representación planteada en estos términos implica que la legitimación de este tipo de gobiernos se encuentra en el consentimiento prestado por aquellos respecto de los cuales será ejercida la autoridad. Es decir, los individuos quedan obligados por aquello que ellos mismo han consentido. Las respuestas angloamericanas y las francesas diferirán al momento de encontrar la génesis de su estructura. La forma en que se construirán las concepciones de soberanía y de cuerpo político, unidas en su vinculado accionar, traerán las características que el sistema democrático desarrollará en los distintos estados a lo largo del propio siglo XIX, pero que resultan la esencia de los regímenes del siglo XXI.

La representación, en definitiva, viene a solucionar el dilema de la democracia en amplias extensiones territoriales y con un demos numeroso. A través de la representación entendida como construcción cultural se consolida la abstracción en lo corpóreo: la asamblea pone en presencia a aquellos que se encuentran a kilómetros de distancia y les da voz.

\section{La irrupción de las masas en el escenario político}

La democracia entendida como democracia representativa, democracia de los modernos, la idea de las garantías de las libertades políticas se desarrolla desde las Revoluciones inglesa, americana y francesa, en el camino del intento por desglosar y ampliar esas libertades y derechos políticos que hacen a su conformación originaria. El impacto de la Revolución Industrial, como fenómeno de explosión demográfica, tanto en Europa como en América determinó la alteración de este sistema, entendido dentro de un contexto clásico. Los hechos acaecidos 
durante las Revoluciones Sociales de 1830 y 1848 pusieron en evidencia la existencia de nuevas fuerzas sociales que modificarían el mapa político que se encontraba trazado.

En 1871 la Comuna de Paris tornara visible el problema al iniciar la democratización de la burguesía. Este fenómeno colocó en un dilema al liberalismo, que comenzó a incurrir en modalidades que llevaban a la alteración de las instituciones de la democracia representativa. Los principios que la regían permanecían visibles pero las prácticas institucionales se alteraban para garantizar los resultados: se manipulaban los sistemas electorales y los distritos electorales, la forma de emisión del sufragio se vio alteradas por cuestionamientos censitarios. La democracia arbitraba las armas para su propio cuestionamiento. A fines del 1800 asistimos al nacimiento de las "masas": clase obrera, clase medias conformadas por pequeños propietarios, artesanos y empleados administrativos y, finalmente, clase campesina. Este formato social dará nacimiento a los llamados partidos políticos de masa. Estas conformaciones pusieron en evidencia la incompatibilidad que existía entre esta nueva forma de manifestación y el "viejo" sistema político.

La depresión económica ocurrida entre los años 1870/1880 colocará en crisis a los regímenes liberales, que intentaban mantener el status quo sin perjuicio del reconocimiento de la aparición de una fuerza política que marcará el diseño que tendrá parte de Europa a fin de la Primera Guerra Mundial: el socialismo.

El socialismo, como uno de los primeros grandes movimientos de masa, cuestionará las formas de inclusión en materia electoral e iniciará el camino del intento en la modificación de las políticas estatales liberales, que le permite a Eric Hobsbawm (2015) preguntarse si se está asistiendo al "dejar hacer".

\section{La ampliación de la democracia}

A fines del siglo XIX comenzó a modificarse la concepción de la participación política en función de la irrupción de los movimientos de masa en el escenario político. El punto de partida basado en la religión, el nacionalismo, la democracia y el socialismo generó la base para la unión de las masas movilizadas. Ello puso en evidencia que las fuerzas políticas imperantes en la época no terminaban por absorber o reconocer la necesidad de insertar a estos nuevos actores políticos. En la idea que no se trata de repúblicas de iguales sino de organizaciones con apoyo de masas, se dejaban fuera de la imagen a fuerzas sociales que resultarían esenciales en los tiempos por venir. La política articulada resultaba incompatible con un sistema político anticuado.

La democratización de las nuevas fuerzas sociales expuso la existencia de una doble problemática: la necesidad de garantizar la legitimidad de la sociedad frente 
a los movimientos de masas y la ineficacia de los Parlamentos, que se traducía en una verdadera crisis de representación.

Los movimientos sociales que se han generado requieren construir mecanismos que permitan administrar a las masas a partir de la canalización de sus pasiones e intereses, para evitar la degradación de las multitudes. Allí la imperiosa necesidad de educar.

La democratización, de la mano del nacionalismo, es esencia de la política europea en esta época. La causa nacional (la autodeterminación y la formación de un estado independiente) proyectan en el concepto del nacionalismo los cambios que acarreará el siglo XX. Este espíritu de época es el que engloba a nuestros autores, quienes ven en las masas y en la democracia cuestiones críticas.

Para Emile Durkheim, el Estado se entiende a partir de un grupo de funcionarios sui generis en el seno del cual se elaboran representaciones que comprometen a la colectividad. Es decir, se trata de un órgano especial destinado a elaborar representaciones con mayor grado de conciencia y reflexión, cuyo valor se proyecta a la colectividad. Su finalidad se centra en dos posibilidades, una individualista y otra mística. La individualista se encarga de proteger los derechos individuales, la mística busca el fin superior de la sociedad por encima de los intereses individuales. Además de ello, debe contener a la tiranía de los grupos secundarios, cuyo destino último deviene en liberar la personalidad individual, al actuar como contrapeso del poder del propio Estado.

El camino del desarrollo de la actividad del Estado le permite definirlo como un órgano de pensamiento social. Pensamiento que se manifiesta desde dos facetas que interactúan entre sí. Por un lado, estamos ante un pensamiento que proviene de la masa colectiva y se difunde en ella (sentimientos, aspiraciones, creencias elaboradas colectivamente) que influirán en las decisiones gubernamentales. Por otro lado, un pensamiento elaborado por el Estado o gobierno, que repercute en la sociedad y modifica las ideas dispersas (ideas que permanecen en el subconsciente social y se comportan de modo automático, irreflexivo y espontáneo). El juego de las dos manifestaciones del pensamiento crea la conciencia central, la "conciencia gubernamental", que resulta particular y no en un mero reflejo de la conciencia colectiva. La "conciencia gubernamental" se concentra en los órganos restringidos, a esferas especiales, donde se sustrae a la mirada de la masa y se desparrama en el conjunto social, donde existe como conciencia generalizada de las situaciones que se plantean y las decisiones que se adoptan. Así, la reflexión colectiva retorna al pensamiento gubernamental para que el estado deje de ser un ser misterioso y aislado. El Estado consulta al Pueblo. 
Así nace el contexto en el que surge uno de los caracteres que definen a la democracia: el poder gubernamental desciende a las capas profundas de la sociedad y de allí recibe una elaboración nueva que vuelve al gobierno. Ello implica control y participación social en las decisiones gubernamentales. La democracia resulta, entonces, en la máxima extensión de la propia conciencia gubernamental, que en una estrecha comunicación con la conciencia social comprende una mayor cantidad de objetos; aquí reside la diferencia con otras posibles formas de gobierno.

La democracia se caracteriza por la comunicación estrecha entre la conciencia gubernamental y la conciencia social que, sumado a la ampliación de la conciencia social en el campo del conocimiento de los objetos, implica un mayor grado de maleabilidad y predisposición al cambio (¿derechos, costumbres, religión?).

Históricamente la democracia ha sido la forma política por la cual la sociedad llega a la conciencia más pura de sí misma y se genera como el régimen más adecuado para la concepción que en la época (principios del siglo XX) se tiene del individuo. La superación moral de la democracia deviene de la aceptación de la ley con inteligencia, lo que implica menos pasividad a consecuencia de la comunicación constante entre el individuo y el Estado. No se trata de una función mecánica. El intercambio entre los individuos y el estado genera una unión recíproca, la que se describe en un marco de evolución por oposición al feudalismo, proceso de máxima oscuridad y dispersión, y a la monarquía centralizada como solución al feudalismo. Ello le permite afirmar que la democracia asciende desde el comienzo de la historia.

El devenir de los inicios del siglo XX ha puesto en evidencia que los mecanismos democráticos generan movimientos políticos que incluyen inercia y actividad a un mismo ritmo. No existe movimiento sino en función de los sentimientos de la masa. Tal situación no impide la capacidad de opresión propia del Estado que condiciona el actuar de las multitudes.

Del mismo modo que otros autores de la época, Durkheim tiene una visión crítica de la democracia, vinculada con la aparición de las masas. La idea que articula en cuanto a la necesidad de generar elecciones de segundo grado evidencia su temor a la actividad descontrolada de dicha manifestación sociopolítica que ancla, básicamente, en la consideración de entender que se ha suscitado una imposibilidad social para la generación de cuadros intermedios, que funcionan como garantía de la libertad del individuo, pero también garantizan la operatividad del actuar estatal.

El conflicto con el fenómeno democrático viene dado esencialmente por la disposición de lo que Durkheim denomina la voluntad del mayor número y que veremos manifestarse también en otros autores. 
Este tema es retomado, de algún modo, en La democracia y los partidos políticos (1979 [1912]) de Moisei Ostrogorski, quien hará referencia a la entronización del número. Este estudio se centra en el funcionamiento del gobierno democrático y los problemas de la sociedad de fines del siglo XIX y principios del siglo XX que, a su criterio, marcan el destino de lo que será la civilización política. Considera que la democracia, como régimen, destruyó los lazos sociales existentes al romper cuadros de la sociedad política (jerarquía de clases y cohesión interior) e implicó la ruptura de los lazos tradicionales de las colectividades. Para ello, generó la aparición de nuevos mecanismos que le permitieran controlar al hombre en el camino de la garantía de la vida social. Lo logró mediante los dispositivos propios de la democracia representativa: la entronización del número. Lo cual solo resuelve los conflictos de modo aparente. La solución a la que se arribó devino en la organización metódica de las masas electorales a través de la formación de partidos políticos, rígidos y permanentes. Los mecanismos utilizados por los partidos políticos con la finalidad de elegir sus líderes han vaciado a la democracia de su efectivo contenido. Las masas son remolcadas por la burguesía y la clase obrera, que han sido condicionadas y absorbidas por el caucus, y en ese camino se ha abstenido de entregarse a la cultura política. La masa, apática e indiferente, permite, en definitiva, este deterioro de la cultura política y es quien ha transformado al partido en la voz de la conciencia política. La actividad desplegada en este sentido estereotipa la opinión al acallar el pensamiento político y eclipsar al individualismo. La adhesión sin reservas a la fe oficial del partido hace nacer la "virtud política suprema". Así, el hombre público posee características más formales, exteriores, que de fondo en formación política. La extensión del sufragio ha permitido que el partido se transforme en la voz del electorado en una suerte de conciencia nacional. Esta "religión nacional" permite a los representantes transformarse en los voceros del gran número, más allá de la masa, lo que les permite apartarse de ella.

La democracia representativa que se genera a partir de estos mecanismos ha provocado la supresión de las "jerarquías intermedias" en demérito de la aparición del gran líder, el gran jefe del partido, lo que desdibuja el sistema democrático.

Robert Michels, en Los Partidos Políticos. Un estudio sociológico de las tendencias oligárquicas de la democracia moderna (2013 [1911]), continúa con la crítica que manifestaron Durkheim y Ostrogorski: la influencia del número. Describe a la democracia desde la perspectiva de la negación de la monarquía a partir del principio de igualdad ante la ley. Las estructuras democráticas no han hecho desaparecer en modo alguno a las clases aristocráticas, sino que estas han transformado su comportamiento en función de los mecanismos eleccionarios que se han generado a partir del nacimiento de los movimientos asamblearios modernos. La aristocracia presenta rasgos democráticos, lo que da por resultado una democracia aristocrática. En este sentido, la democracia otorga externamente rasgos 
igualitarios, pero tiene a una aristocracia (u oligarquía) de partidos políticos que, en definitiva, harán a su constitución. La democracia es inconcebible sin una organización (consecuencia de la cooperación que le resulta indispensable). Esta organización le permite llevar adelante la voluntad colectiva, como condición esencial para la lucha política de las masas. El sistema así descripto y consolidado como aquel gobierno que las masas han hecho propio no impide la aparición del concepto de delegación, lo que permite sostener que resulta imposible la desaparición total de grupos oligárquicos. De allí la utilización de estímulos de sugestión.

Resulta más fácil ejercer dominación sobre grandes grupos que sobre pequeñas audiencias. La gestación de las influencias a las que puede someterse a las masas le permite sostener al autor que el individuo se desvanece al desaparecer su personalidad en beneficio de la patología de la multitud. Esto traerá como consecuencia la desaparición de la responsabilidad individual y el nacimiento de la soberanía de la masa, que obviamente, carece de entidad. Se ha puesto en evidencia la impotencia de la democracia directa y el poder de la democracia indirecta (representativa) que no hace otra cosa que realzar la influencia del número. Lo que se ha colocado sobre la mesa no es otra cosa que la idea de la representación por delegación en un marco de respeto por el principio de igualdad ante la ley en el ámbito electoral: todos son elegibles y todos pueden elegir.

Aunque no será exactamente así, producto de la especialización técnica que deberán poseer aquellos que se presenten como elegibles. Uno de los atributos esenciales del liderazgo ancla en la idea de la conducción experta. Así la masa pierde poder en beneficio de la masa de líderes que se emancipan e independizan del control del ente de pertenencia. Allí se encuentra las manifestaciones oligárquicas/aristocráticas de la democracia moderna: minoría dirigentes sobre mayorías dirigidas. Esto es lo que se ha dado en llamar "La Era de la Democracia", que no implica otra cosa que una ampliación gradual de los privilegios de la clase dirigente.

Ahora bien, lo que Michaels sostiene es que el crecimiento de la democracia como régimen político representativo arrastra a la declinación a la democracia en materia de política partidaria. El poder de los líderes partidarios resulta directamente proporcional al tamaño de la organización partidaria, lo que trae aparejado el nacimiento de una "burocracia jerárquica de tendencia oligárquica y con necesidades técnicas". Por eso, la democracia ha devenido en una forma de organización que debe funcionar de modo armónico. De no funcionar de dicha manera se privilegiará la organización por encima del propio sistema.

La aparición de la figura del líder como profesional político lo coloca, de manera automática, por encima de la masa, lo que a su vez justifica su diferenciación práctica y moral. Ello pone de manifiesto la inmadurez política de la masa, lo que torna 
imposible de aplicación la concepción de la soberanía popular. Así, se afirma que la democracia es la encargada de limitar a la propia democracia. La derivación razonada de esta afirmación permite que el autor sostenga que la democracia terminará por transformarse en el gobierno de los mejores, una aristocracia. La democracia de los líderes. Ello redunda en la concentración del manejo de los asuntos políticos que es donde mejor se observa el desarrollo de las manifestaciones oligárquicas. Ello permite que el autor evalué la factibilidad de la democracia como sistema, por cuanto la naturalidad con que las oligarquías se conforman dentro de la democracia deviene de su necesidad orgánica: la masa nunca será la encargada de gobernar (sino in abstracto). La inmadurez que caracteriza a la masa resulta ínsita a la misma, producto de la naturaleza del hombre que requiere se lo guíe.

Resulta interesante como Michels, Durkheim y Ostrogorski, con distintos puntos de partida y en análisis diferenciados de la temática seleccionada, arriban a la crítica de la cuestión de los mecanismos numéricos. Una elite que gobierna y representa a un número de ciudadanos que la superan en cantidad, y se arroga la prerrogativa de administrar y organizar. Una asimilación casi constante a la idea del número, a la idea de la multitud que se manifiesta en el orden político, solo al efecto de legitimar el régimen.

Con Max Weber retomamos el camino trazado por Durkheim, Ostrogorski y Michels, mediante el cual podemos hallar una vinculación entre las manifestaciones democráticas y lo que ya denominamos sus expresiones numéricas. En el caso de Max Weber, el principio del pequeño número. Parece ser recurrente la idea conforme la cual la democracia de fines del siglo XIX y principios del siglo XX se asienta sobre criterios de mayorías y minorías. Cómo entender el comportamiento político de las masas en el campo de lo democrático bajo la idea del número. Cómo la masa expresa su voluntad en mayorías y como las elites minoritarias se hacen del manejo de la política, a niveles aristocráticos / oligárquicos o en cabeza de líderes carismáticos.

Otro autor que resulta interesante en este recorrido es Carl Schmitt a partir de su texto Sobre el Parlamentarismo(2). Este escrito se inicia con un planteo en el que se distingue parlamento de democracia. Un aspecto del tema que hasta este momento no había sido deslindado, sino que se observaban como paradigmas integrados. En el seno del Parlamento se manifiesta la democracia. Hace hincapié en reconocer que a principios del siglo XX la distinción entre Parlamento y democracia no es clara, sin perjuicio de lo cual reconoce la existencia de una contradicción: no es lo mismo hablar de ideas liberales parlamentarias que de ideas

(2) Interesante resulta destacar que es lo único que se edita con posterioridad a la finalización de la primera guerra mundial. 
democráticas de masas. En este sentido se permite afirmar que, si el Parlamento se comprende como un método de gobierno o un sistema político, resulta útil. Pero si se parte de la idea de entender al parlamento como un medio de selección de líderes, en 1920 ha dejado de funcionar como tal. Se mantiene como ámbito de discusión, pero a partir de la aparición de la democracia de masa se ha tornado en una formalidad vacía de contenido.

El Parlamentarismo, entendido como el gobierno de la discusión (propio de la idea del Liberalismo) se distingue de la democracia, como concepto aristotélico (de justicia) fundado en la idea de la homogeneidad y la destrucción de la heterogeneidad: a cada igualdad se corresponde una desigualdad. Ello implica la posibilidad de excluir a una minoría de una población dominada por el Estado y que esto no traiga aparejado que haya menos democracia. En este sendero, Schmitt considera que el mecanismo de sufragio universal no es fundamento esencial de la democracia, sino que se trata, simplemente, de una razonable muestra de igualdad sustancial dentro de un círculo de iguales, consecuencia de la homogeneidad que no deviene del pensamiento democrático sino del ideario liberal. El problema que presenta el parlamentarismo a principios del siglo XX radica en el desarrollo de la democracia de masas, lo que arrastra a la crisis de la democracia, tal y como era comprendida hasta entonces.

La identidad democrática como incuestionable voluntad del pueblo puede ser expresada en cualquier forma. No existe ningún cuerpo colegiado que pueda oponerse a tal voluntad. Así, el parlamento pierde su razón de ser, ya que su propia existencia depende de la discusión (bajo la idea liberal). Por eso la democracia y el liberalismo forman una identidad precaria. Se habla, entonces, de la voluntad del pueblo, la que puede observarse en elecciones o en procesos de aclamación. Así, el acto electoral no es la democracia, como tampoco lo es el conteo de sufragios. Solo se presenta así en su aspecto técnico que derivará en el parlamento como maquinaria artificial, producto del devenir histórico anclado en el ideario liberal como oposición al absolutismo. En materia de aclamación, nos encontramos ante los dictadores cesaristas, como expresión directa de la sustancia y fuerza democrática (homogeneidad democrática).

La democracia históricamente nació como el enemigo de la monarquía y así se ha visto (casi confundida) con el liberalismo y la libertad. Por su carencia de contenidos políticos propios, y entendida como una forma de organización, debe analizarse cuál es su valor.

Este autor elige describir la democracia desde una sucesión de identidades:

- La identidad de la mayoría se identifica con la identidad de la minoría vencida. 
- Identidad entre la ley y la voluntad del pueblo.

- Identidad Estado y pueblo.

- Suma de identidades.

Schmitt entiende que la identidad entre la mayoría que se identifica con la minoría vencida se desprende de las concepciones de libertad de Locke y de voluntad general de Rousseau. La ley es la voz de la voluntad de los ciudadanos libres, ya que no existe la aprobación del contenido concreto de la ley, sino su aprobación in abstracto. Lo que en términos de Rousseau pone en evidencia el verdadero concepto de libertad, conforme el cual el hombre es verdaderamente libre cuando su voluntad coincide con la voluntad general, cualquier actitud en contrario lo esclavizaría. Esto le permite concluir al autor en análisis, que el gobierno de la minoría puede condicionar a la mayoría y que esto no sería contrario a principios democráticos.

Sin perjuicio de ello, la negación de la propia libertad (entendida en términos russonianos) deja a salvo la identidad entre la ley y la voluntad del pueblo a partir de la configuración de la ampliación del derecho al voto. Este pedido de emisión de opiniones genera la identidad entre Estado y Pueblo, contexto que permite desarrollar la suma de las identidades (gobernantes/gobernados; dominantes/dominados; pueblo/representación; Estados/pueblo; Estados/ley; cuantitativo (mayoría numérica - unanimidad)/cualitativo (lo justo de la ley).

Se trata de la generación de identificaciones. No es igualdad, es identificación. Las instituciones de la democracia que hacen a las identidades descriptas no pueden forjar por ellas mismas identidades absolutas y directas, siempre existirá distanciamiento entre la igualdad real y la identificación. Es aquí donde entra en juego la noción del término voluntad. ¿Cómo se forma la voluntad? Según este autor, a partir de la educación: es la identificación entre la voluntad de quien educa y la del pueblo educado lo que consolida la idea de una dictadura, que no es más que la supresión de la democracia en nombre de su creación. Entiende, entonces, que la dictadura no es contraria a la democracia, sino que el poder político del dictador forma a la voluntad del pueblo y mantiene la identidad que hace a la democracia. El problema radicará en quien será el poseedor de los medios que permitan formar esa voluntad. La importancia quedará enraizada, entonces, en la posesión de los medios para generar la identificación.

Schmitt, vuelve también sobre el aspecto numérico, pero en el contexto del acto electoral, y solo como aspecto técnico de la cuestión que analiza. Sí intentáramos conformar un bloque con los pensamientos de los autores reseñados y al solo efecto de describir la cuestión "democracia" nos encontramos ante una evidente 
crítica al régimen. Ya planteamos en los párrafos precedentes la recurrente mirada puesta en la masa a la que se le adjudica la posibilidad (o imposibilidad) de llevar adelante su decisión o poner en práctica su voluntad, y el temor que esto puede generar. La voluntad del mayor número, la entronización del número, la influencia del número, la patología de la multitud, la soberanía de la masa, el interés de la mayoría, el principio del pequeño número, el acto electoral definido por la mayoría, hacen referencia constante a la necesidad de reconocer un cambio de paradigma que al orden político imperante parece costarle absorber.

El recorrido emprendido, a partir de la concepción que los autores reseñados hacen de la democracia en un contexto de cambios sociales y de concepciones políticas a fin del siglo XIX e inicios del siglo XX, nos muestra que los desafíos emprendidos al momento de analizar los principios democráticos y liberales en un marco de cambios sociales que evidencian la imposibilidad de adaptación de las estructuras dadas antes alteraciones que resultan de difícil absorción.

\section{El ascenso de las fuerzas liberales y la destrucción de la democracia}

El siglo XX se iniciará con un conflicto armado a escala mundial que concluirá en 1918 con la llamada Paz de Versalles(3). Queda plasmado en ellos: el derrumbamiento de los regímenes europeos y la eclosión del régimen bolchevique (la Revolución Rusa se había producido en 1917); el control sobre Alemania; la reestructuración del mapa europeo a consecuencia de la desintegración de los imperios que habían sido reemplazados por una sucesión de estados de esencia nacionalista. Asimismo, se establecían las pautas de política nacional de las potencias vencidas y se intentó arbitrar un mecanismo para evitar un nuevo conflicto armado, la denominada Sociedad de las Naciones.

La democratización de la burguesía, ocurrida a fin del siglo XIX, también había generado la aparición de un nuevo fenómeno: el nacionalismo, que tenía trasfondo político e ideológico. Las manifestaciones nacionalistas se concentraban en la idea de la autodeterminación nacional que ancla en la formación de estados soberanos e independientes que se definen a sí mismos en términos étnicos y lingüísticos (Hobsbawm, 2015, p. 135). El Estado ha creado la conciencia de la nacionalidad como construcción de pertenencia a una comunidad imaginaria que tendrá por exigencia fundamental la educación y la alfabetización, es decir, un sistema educativo organizado.

(3) Se trata, en realidad, de una serie de tratados que ponen fin a la Gran Guerra. El Tratado de Versalles pacta la paz con Alemania; el Tratado de Saint-Germain con Austria; el Tratado del Trianon con Hungría; el Tratado de Sèvres con Turquía y el Tratado de Neuilly con Bulgaria. 
Este fenómeno se desarrolla al mismo tiempo que la concepción política de la masa. Ello implica que cuando se habla de nacionalismo en los términos descriptos se hace hincapié en la idea de la educación de las masas.

Así, la idea parte de una generación vertical de una homogeneización lingüística y administrativa. Pertenecer, sentirse incluido, implica la asimilación en términos positivos y la exclusión en términos negativos, que se traduce en xenofobia. La corriente nacionalista tomará una mayor fuerza con posterioridad a la finalización de la Primera Guerra Mundial en un contexto de crisis del liberalismo, de la democracia y de la representación que derivará en los llamados regímenes totalitarios.

El fenómeno del nacionalismo se vincula fuertemente con la idea de la aparición del concepto de "masa". En La Nacionalización de las Masas (2007 [1974]) George Mosse toma como punto de partida el concepto de voluntad general articulado por Jean Jacques Rousseau que elabora los principios de la conciencia nacional y de la soberanía del pueblo como ideal, que lleva implícito al culto a la Nación. EL pueblo caótico se transforma en movimiento de masa y comparte la creencia de la unidad popular mediante una mística nacional. En Alemania, a inicio del siglo XIX se estimularán por dos medios: Volk y el desarrollo del movimiento político de masas. La suma de la masa más el culto (masa + culto) da por resultado la liturgia política, a lo que este autor caracteriza como "nueva política", en honor a lo masivo y lo popular. La liturgia nacionalista se asentará sobre la materialización de los mitos (religiosos / cristiano + tamiz pagano). El Romanticismo Alemán de principios del siglo XIX y el cristianismo generaron el culto nacional alemán sostenido por símbolos: fuegos sagrados, banderas, canciones y monumentos nacionales. La gestación de estas presencias, por poner solo un ejemplo, plantea una búsqueda de representar la voluntad general, que alcanzará su cenit en el momento en que el pueblo rinda culto a sus propias pasiones.

Las imágenes, metáforas y giros retóricos con que se construyen las ideologías nacionalistas son esencialmente recursos, expedientes culturales, utilizados con la finalidad de hacer explícito uno u otros aspectos del proceso más amplio de autoredefinición colectiva, la finalidad expresar el orgullo esencialista o la esperanza epocalistas en formas simbólicas específicas que pueden ser descritas, desarrolladas, celebradas y usadas antes que vagamente sentidas (...) (p. 21).

La democracia liberal entendida en su marco regulatorio de democracia parlamentaria exige acciones de consenso básicos dentro de una población que permita conciliar y desactivar conflictos internos. Los procesos de prosperidad económica facilitan el desarrollo del sistema. Las crisis económicas producidas por la Primera Guerra Mundial y el proceso de depresión económica que se generará durante la década del 20 convalida más la idea de un gobierno que no funcionaba 
adecuadamente y ciudadanos desencantados que habían dejado de confiar en las instituciones. Ello sumado al movimiento socialista amenazante y al resentimiento de los nacionalismos consecuencia de la paz de 1918/1920 permitieron la eclosión de movimientos de extrema derecha. A partir de la década del 20 se inician los procesos que marcarán la crisis de las democracias representativas. Italia y Alemania pondrán en evidencia la gravedad de la crisis institucional.

En 1928 Joseph Goebbels escribía, y nos mostraba en qué consistían estos planteos “(...) hace mucho que madura la caída del Parlamentarismo. Nosotros acabaremos con él. Ya estoy harto de esta comedia. No tendrán muchas oportunidades de verme en su Alta Asamblea (...)" (Rosanvallon, 2015, p. 124).

La propaganda (junto a la utilización del terror) redunda en un instrumento propio del poder que, mediante la utilización de formas veladas y amenazadoras, profecías cuasi científicas y afirmaciones que sostienen y justifican comportamientos violentos esenciales al régimen, articulan la propia estructura del sistema. Este tipo de propaganda implicará la generación artificial de la conciencia nacional explotando la idea del complot. Nada une más a un pueblo que un enemigo común. La unidad de un pueblo parte de la idea de la igualdad natural que implica la expulsión del desigual. El análisis posterior que se efectuó por distintos autores acerca del fenómeno fascismo / totalitarismo partió de las premisas de Arendt(4) y por crítica o aprobación amplió el universo a la comprensión del fenómeno.

Claude Lefort, en una conferencia efectuada en 1996, critica la postura de Arendt en cuanto no incluye al fascismo italiano como manifestación totalitaria. A este respecto caracteriza al fascismo italiano como una orientación política nueva y un modelo revolucionario antidemocrático.

Así lo entiende también Robert Paxton, que caracteriza al fascismo como una revolución, que comprende el cambio de concepción entre lo público y lo privado; la concepción del ciudadano como aquel que participa en la multitud y el cese de la individualidad en pos de la colectividad. Asimismo, hará hincapié entre los que se consideran los "ismos" clásicos (conservadurismo, liberalismo y socialismo), que con apoyo en las emociones y en los sentimientos populares se sostienen en sistemas filosóficos sistemáticos y el fascismo como creación deliberada para la política de masas. Siguiendo con el argumento de Paxton, Bobbio (2008) ahonda

(4) El fenómeno fue analizado de manera sistemática por Hanna Arendt, que en 1951 publica por primera vez Los orígenes del totalitarismo (cuya última actualización realiza en 1966). Su análisis se circunscribirá a dos manifestaciones de totalitarismo el nazismo y el stalinismo soviético entre los años 1945 - 1953. Arendt analizó las manifestaciones totalitarias desde dos ángulos: el terror y la propaganda. El terror que provocará el sometimiento de la población que hace a la esencia del régimen y dependiendo de sus manifestaciones tornará innecesaria la propaganda posterior. 
en los elementos que hacen a esa característica revolucionaria. Así, sostenía que, entre otras cosas, el fascismo tenía una profunda impronta antidemocrática porque era anti igualitario y anti pacifista. "El llamado ascenso de las masas, el achatamiento, la igualación democrática, el decaimiento del principio aristocrático, para el cual en todo tiempo hubo superiores e inferiores y sólo a los primeros corresponde la dirección espiritualidad y política de la sociedad (...)” (5) (p. 55). En este sentido, afirma la "democracia con su furia niveladora, con su confusión del bajo y del alto, con sus supersticiones internacionalista, favorece el avance de los inferiores y amenaza con llevar a la ruina a la raza de los dominadores (...)" (p. 55).

Será Emilio Gentile quien, a partir de la crítica a la elaboración de Hanna Arendt, propondrá estudiar el fascismo como movimiento político, social y cultural que surge a consecuencia de los conflictos y tensiones propias de la sociedad de masa, de la violenta aceleración del proceso que movilización social y la modernización que de manifiesta con posterioridad a la Primera Guerra Mundial. Así queda caracterizado bajo los auspicios de la encarnación viviente de la nación, la que entiende como comunidad orgánica, compacta, unitaria y homogénea. Pone de manifiesto que el primer movimiento totalitario resulto en el fascismo italiano y que luego se proyectó hacia el nazismo y el bolcheviquismo.

No pretendemos efectuar un desarrollo pormenorizado de los factores que contribuyeron a las manifestaciones fascistas/totalitarias. Simplemente recalcar que se trata, en el caso de fascismo italianos y del nacionalsocialismo alemán, de una reacción ante un sistema democrático representativo que no recepta adecuadamente las nuevas manifestaciones y reclamos políticos que se realizan a partir de la consolidación de las políticas de masas. En el caso concreto de Italia y Alemania, en el proceso posterior a la Primera Guerra Mundial no se dio respuesta adecuada a los reclamos que una nueva sociedad les planteaba. El nacionalismo cooptó a las masas y la nueva política. En términos de George Mosse, le entregó a través de los ritos, los símbolos y la incorporación del poder al hombre/líder el ideal del cuerpo único de reconocimiento que la masa exigía.

Las consecuencias devastaron Europa y cuando llegó el momento de reconstrucción, la democracia representativa fue nuevamente la respuesta. Los procesos democráticos que se consolidaron a partir de la década del 50 se conformaron bajo los auspicios de valores que apuntaban a la solución pacífica de conflictos

(5) Bobbio recoge la idea del componente revolucionario del fascismo no necesariamente para convalidarlo. Irá desagregando los distintos elementos que considera ínsitos al fenómeno para justificar su objetivo: volver a poner al poder en manos de las elites preparadas para ejercerlo y sacárselo a la masa. La motivación se encuentra dada en los componentes que integran el entramado de la justificación del fascismo, sin dejar de cuestionar la inexistencia de expresiones ideológicas: antisocialismo, antiliberalismo, antiigualitarimos, antidemocrático, antipacifista. 
EL SENTIDO DE LA REPRESENTACIÓN POLÍTICA: DE LA EVOLUCIÓN DEMOCRÁTICA A LA inVOluCión TOTALITARIA - Debora BURSZTYN y AlejandRa P. DíaZ (PP. 679-702)

sociales; la eliminación de la violencia institucional; la frecuente alternancia de la clase política y la tolerancia a partir de ejercicio de reglas que se inspiran en procesos de naturaleza universal (6).

Pero con la llegada del nuevo siglo asistimos a una nueva crisis, que obviamente encuentra su génesis en hechos precedentes.

\section{La fatiga de la democracia al inicio de siglo XXI}

El fin de la guerra fría provocó, junto a la crisis del marxismo un importante vacío ideológico que, en gran parte, se vio ocupado por el sistema capitalista ligado al neoliberalismo que encuentra su fuerza de choque en los procesos de la globalización. En ello se focalizan, de alguna manera, las transformaciones que derivaron en integraciones sociales, pero también en manifestaciones de segmentación. Asimismo, pondrá en evidencia el debilitamiento en que los regímenes democráticos se van viendo inmersos. El retroceso de la democracia empieza en las urnas y el sistema se erosiona de manera imperceptible. Los gobiernos, mediante acciones convalidadas por los órganos legislativos o por tribunales superiores, bajo pretextos de objetivos públicos legítimos, como el combate contra la corrupción, la garantía de la transparencia electoral, la mejora de la calidad democrática, el potenciamiento de la seguridad nacional, provocarán la aparición de fenómenos de características diferenciadas que combinan regímenes democráticos con regímenes autoritarios denominados en términos generales como regímenes o democracias iliberales (7). Los informes brindados por Democracy Index en los años 2010 (8) y 2015(9) dejan constancia de una democracia bajo stress, donde se acusa a los gobernantes y políticos de provocar el alejamiento de los ciudadanos, quienes resultan desentendidos de la política y de la propia democracia, dándose la paradoja de un sistema previsto para la participación del pueblo donde el demos se encuentra ausente. Freedom House en 2016(10) nos informa que el pueblo so-

(6) Órgano legislativo electivo; órgano administrativo; universalización del sufragio; igualdad en el voto; procesos electorales libres en ejercicio de oposiciones partidarias; aplicación del principio de mayorías; respeto por las minorías.

(7) La literatura al respecto es muy numerosa, estableciendo matices entre el mismo fenómeno, a saber: formas democráticas incompletas; formas democráticas de transición; regímenes híbridos; semidemocracia; democracia virtual; democracia electoral; presudodemocracia; semiautortarismo; autoritarismo blando; autoritarismo electoral; autoritarismo competitivo.

(8) Recuperado de http://graphics.eiu.com/PDF/Democracy_Index_2010_web.pdf [Fecha de consulta: 02/03/2021].

(9) Recuperado de https://www.yabiladi.com/img/content/EIU-Democracy-Index-2015.pdf [Fecha de consulta: 02/03/2021].

(10) Recuperado de https://freedomhouse.org/sites/default/files/FH_FITW_Report_2016.pdf [Fecha de consulta: 02/03/2021]. 
berano desconfía. ¿De qué desconfía? De los políticos y su actuar corrupto; de los partidos políticos a los que considera desacreditados; de los gobernantes y representantes que destinan su actuar a su propia satisfacción en demérito del bien público. ¿Cómo se comporta este demos? Abandona las instituciones y la militancia política, se abstienen de participar en los procesos electorales y deja de comprometerse con la democracia. Entonces la democracia representativa se ve viciada y el malestar que se genera encuentra motivos donde abrevar. Quienes gobiernan se consideran a sí mismos una casta privilegiada, ante lo cual la desconfianza en las instituciones y los partidos convive con la apatía ciudadana en un marco de crecimiento de la desigualdad social. Este fenómeno encuentra alguna respuesta en la aparición de jefes pragmáticos y personalistas, aquel que de manera directa y sin eufemismos parece comprender donde se encuentra la falla del régimen.

A las afirmaciones brindadas por Francis Fukuyama (1994) o Robert Dahl (2004), conforme las cuales veían a una democracia triunfante y vigorosa, Colin Crouch (2004) se permitía afirmar que el debate electoral público se circunscribe a un mero espectáculo que controlan equipos rivales de profesionales en técnicas de seducción, bajo la premisa que la mayor parte de los ciudadanos resultan pasivos e inactivos y la política se desarrolla entre bastidores, a través de un proceso de interacciones entre gobiernos elegidos y elites, encargadas de representar intereses empresarios.

En este mismo contexto, Pierre Rosanvallon (2007) ha desarrollado el concepto de "contrademocracia", para caracterizar de alguna manera estos nuevos fenómenos. Ha distinguido dentro de la concepción de democracia dos institutos: la legitimidad y la confianza. La legitimidad en su calidad jurídica procedimental (la elección) y la confianza como institución invisible que amplía la calidad de la legitimidad; permite su continuidad y ahorra los mecanismos de control y prueba. Su observación radica en que considera que los mismos se encuentran disociados y generan reacciones. Por un lado, la necesidad de reforzar la legitimidad procedimental y por el otro, la organización de la desconfianza. Si retomamos los términos de Constant, se hablaría de desconfianza antigua, que rechaza los poderes arbitrarios impuestos a la sociedad y la desconfianza moderna, la contingencia de constatar los posibles yerros de los regímenes surgidos de la voluntad popular.

La democracia electoral representativa reconoce su antagonista en la contrademocracia, entendida como la democracia de la desconfianza, de los poderes indirectos diseminados en la sociedad, entendidos como poder de control, de obstrucción y de puesta a prueba, visto desde la perspectiva del individuo autónomo como miembro de la comunidad cívica sobre la base del principio de igualdad. 


\section{Conclusión}

Como hemos visto en este camino histórico, a través del recorrido del pensamiento político, la democracia ha tenido fuertísimas críticas y numerosas crisis. La idea que se articula desde la igualdad en la participación en la toma de decisiones, y las formas de elegir a quienes nos gobiernan siempre fueron cuestionadas. Aún hoy se suelen escuchar voces minoritarias revindicando propuestas alternativas.

A principios del siglo XIX, Tocqueville nos hablaba de la "igualación de las condiciones" y su temor a la posible tiranía de las mayorías, temor que quedaba atemperado por la propia naturaleza de la democracia. Democracia que Lincoln definió como "el gobierno del pueblo, por el pueblo y para el pueblo". Ninguno de ellos le dio los rasgos que a fines del mismo siglo e inicios del siguiente nos presentaron los autores analizados. En pocos años, un sistema que se presentaba como la garantía de la libertad se había transformado en un régimen que había distorsionado su propia naturaleza, o por lo menos la situación política, social, ideológica y filosófica, así parecía entenderlo.

El cuestionamiento al concepto y los valores democráticos que se fundan en el ejercicio de la libertad, la participación y la igualdad derivaron en sistemas que, en nombre de la solución, generaron uno de los momentos más oscuros de la historia de Occidente.

Casi un siglo después, vuelven a encenderse las luces de alerta sobre el tema. Sin embargo, hay diferencias sustanciales. La democracia del siglo XXI viene apoyada en la concepción de que nos encontramos ante un régimen deseable y valorado positivamente por todos los países, incluso por aquellos que no la tienen o la enarbolan como mascarada. La comunidad internacional fue consecuente con su instauración y su defensa, pero el cambio de siglo se dio dentro de un contexto global caracterizado por la decadencia de una clase política tradicional que no tuvo eficiencia en dar respuesta, ni tuvo la capacidad de adaptación a las condiciones que se le han exigido. Asimismo, se han producido una multiplicidad de demandas a una democracia a la que le cuesta prestar atención y que no puede satisfacer las necesidades que le son impuestas.

La combinación de ambos factores genera una nueva crítica al sistema que lo erosiona una vez más. La crisis global que implica la pandemia en la que nos encontramos inmersos socaba desde las decisiones tomadas acertadamente hasta otras que evidencian la ineficiencia e inoperancia de los gobiernos democráticos y que afectan libertades y derechos fundamentales. Situación que, además, provoca más demandas sobre la democracia creando un proceso de descontento con el sistema. Como en un loop, la historia parece repetirse. 


\section{Bibliografía}

Abal Medina, J. M. y Nejamkis, F. (2004). Modelos de política: una mirada desde el Estado y la Ciudadanía en clave latinoamericana. En A. García Raggio y otros, $L a$ política en conflicto (pp. 111-146). Buenos Aires. Editorial Prometeo.

Aguilar, E. (2008). Benjamin Constant. El liberalismo y la democracia. Recuperado de https://www.caminosdelalibertad.com/notas/2-enrique-aguilar [Fecha de consulta: $27 / 02 / 2021]$.

Arendt, H. (2015). Los orígenes del Totalitarismo. Madrid: Alianza Editorial.

Arendt, H. (2017). Sobre la revolución. Madrid: Alianza Editorial.

Bobbio, N. (2008). Ensayo sobre el Fascismo. Buenos Aires: Editorial Prometeo.

Bobbio, N. (2009). Teoría General de la Política. Madrid: Editorial Trotta.

Bobbio, N. (2018). El futuro de la democracia. México: Editorial Crítica.

Bobbio, N. (2018). Liberalismo y democracia. México: Editorial Fondo de Cultura Económica.

Collier, D. y Levitsky, S. (1997). Democracy with adjectives conceptual innovation in comparative research. World Politics, Vol. 49, No. 3, April, (pp. 430-451).

Crouch, C. (2004). Posdemocracia. Madrid: Editorial Taurus.

Dahl, R. (2004). La Democracia. PostData 10 (pp. 11-55).

Durkheim, E. (2006). Lecciones de sociología. Física de las costumbres y del derecho. Granada: Editorial Comares.

Fukuyama, F. El fin de la historia y el último hombre. Madrid. Editorial Planeta.

Furet, F. (1980). Pensar la revolución francesa. Barcelona: Ediciones Petrel.

Furet, F. (2016). La Revolución Francesa en debate. De la utopía liberadora al desencanto de las democracias contemporáneas. Buenos Aires: Editorial Siglo XXI.

Gentile, E. (2004). Fascismo. Historia e interpretación. Madrid: Alianza Editorial.

Gentile, E. (2017). El líder y la masa. La génesis de la democracia recitativa. Buenos Aires: Editorial Edhasa. 
Gentile, E. (2018). La mentira del pueblo soberano en la democracia. Madrid: Alianza Editorial.

Geertz, C. (2006). La interpretación de las culturas. Barcelona: Editorial Gedisa.

Hobswam, E. (2015). La era del imperio. Buenos Aires: Crítica Grupo Editorial Planeta.

Hobsbawm, E. y Ranger, T. (2016). La invención de la tradición. Barcelona: Editorial Crítica.

Hobswam, E. (2018). Nación y nacionalismos desde 1870. Barcelona: Editorial Crítica.

Levitsky, S. y Way, L. A. (2004). Elecciones sin democracia. El surgimiento del autoritarismo competitivo. Estudios Políticos, № 24 (pp. 159-176).

Levitsky, S. y Ziblatt, D. (2018). Como mueren las democracias. Buenos Aires: Editorial Ariel.

Lefort, C. (2011). Democracia y representación. Buenos Aires: Editorial Prometeo.

Lefort, C. (2014). El pueblo y el poder. Buenos Aires: Editorial Prometeo.

Michels, R. (2013). Los partidos políticos. Un estudio sociológico de las tendencias oligárquicas de la democracia moderna. Volumen 1. Buenos Aires: Editorial Amorrortu.

Morgan, E. S. (2006). La invención del pueblo. El surgimiento de la soberanía popular en Inglaterra y Estados Unidos. Buenos Aires: Siglo XXI.

Mosse, G. L. (2007). La Nacionalización de las masas. Simbolismo político y movimientos de masas en Alemania desde las guerras napoleónicas al Tercer Reich. Buenos Aires: Siglo XXI.

Nun, J. (2015). Democracia ¿Gobierno del pueblo o Gobierno de los políticos? Buenos Aires: Capital Intelectual.

O'Donnell, G. (1994). Delegative Democracy. Journal of Democracy, Vol. 5, No 1 , January (pp. 55-69).

O’Donnell, G. y Schmitter, P. (2010). Transiciones desde un gobierno autoritario. Buenos Aires. Editorial Prometeo. 
Ostrogorski M. (1979). La democratie et les partis politique. France: Editions Du Seuil.

Paxton, R. O. (2004). Anatomía del fascismo. Barcelona: Editorial Península.

Rosanvallon, P. (2007). La contrademocracia. La política en la era de la desconfianza. Buenos Aires: Editorial Manantial.

Rosanvallon, P. (2015). El Buen Gobierno. Buenos Aires: Editorial Manantial.

Rosanvallon, P. (2020). El siglo del populismo. Historia, Teoría y crítica. Buenos Aires: Editorial Manantial.

Sartori, G. (1999). En defensa de la representación. Claves de Razón Práctica, No 91.

Schedler, A. (2004). Elecciones sin democracia. El menú de la manipulación electoral. Estudios Políticos, № 24 (pp. 137-156).

Schmitt, C. (2002). Sobre el parlamentarismo. España: Editorial Tecnos.

Weber, M. (2008). Escritos políticos. Madrid: Alianza Editorial.

Zakaria, F. (1997). The rise of iliberal democracy. Foreign Affairs, Volume 76, № 6, November/December (pp. 22-43).

Fecha de recepción: 31-03-2021 Fecha de aceptación: 20-08-2021 